
impairment in children and adults

Pirozzo S, Papinczak T, Glasziou P. Whispered voice test for screening for hearing impairment in adults and children: systematic review. BMJ 2003;327:967.

\title{
$Q$ Is the whispered voice test accurate for detecting hearing impairment in children and adults?
}

\section{METHODS}

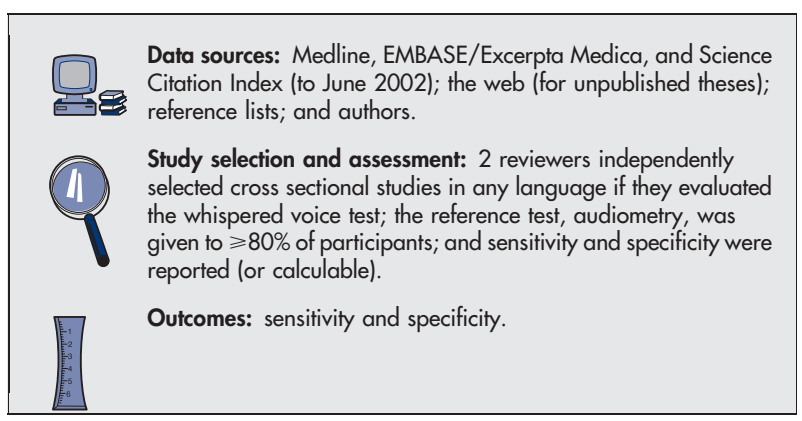

\section{MAIN RESULTS}

8 English language studies were included. 4 studies included 256 adults (age range 17-96 y). The prevalence of hearing impairment ranged from $26-61 \%$. 3 studies used similar techniques for the whispered voice test and a $30 \mathrm{~dB}$ positivity threshold for hearing impairment by audiometry (sensitivity $90 \%$ or $100 \%$, specificity 80 $87 \%)$. 1 study used a different technique for the test and a $40 \mathrm{~dB}$ positivity threshold; the results were reported such that overall sensitivity and specificity could not be calculated. At a sensitivity of $90 \%$, the specificity was $70 \%$ (table). 4 studies included 716 children (age range 3-12 y). The prevalence of hearing impairment ranged from $9-31 \%$. All studies used slightly different techniques for the test, and positivity thresholds ranged from $20-35 \mathrm{~dB}$ (sensitivity $80-96 \%$, specificity $90-98 \%$ ) (table).

\section{CONCLUSION}

The whispered voice test is accurate for detecting hearing impairment in children and adults

For correspondence: $S$ Pirozzo, School of Population Health, University of Queensland, Herston, Queensland, Australia. s.pirozzo@sph.uq.edu.au Source of funding: National Health and Medical Research Council.

\section{Commentary}

creening for hearing impairment in older age groups is recommended, ${ }^{1}$ although the benefit of screening children during the first 4 years of life has not been established. ${ }^{2}$ One screening method is the whispered voice test, the subject of this systematic review by Pirozzo et al.

The methodological quality of the studies included in this review was modest: only 2 of 8 studies met all quality criteria. Studies in children had the poorest quality. The specificity and sensitivity were high in all 8 studies despite the use of 6 different techniques. For the paediatric population, the sensitivity was lower, risking failure to identify hearing loss in some children.

The whispered voice test is a simple and accurate screening tool. The recommended standardised procedure for conducting this test is to have the examiner stand an arm's length behind the seated client. After exhaling, the examiner whispers a combination of numbers and letters as the client gently occludes one of their auditory canals with a finger while rubbing the tragus in a circular motion. The client is asked to repeat the sequence, and hearing is considered normal if the client responds correctly. If the client responds incorrectly, the test is repeated using a different number/letter combination. The client "passes" if able to correctly repeat 3 of the 6 numbers or letters.

An area of concern is the reliability of the test. Variation in the loudness of the whisper and clinician failure to exhale before whispering can lead to variable results in the same patients when administered by different clinicians. None of the studies were done in primary care settings, and the clinicians were specialists rather than primary care practitioners. The results are particularly relevant to clinicians working with elderly populations. Further research is required to evaluate the use of the test in primary care settings and with children.

Joanne Opsteen, RN(EC), BScN East End Community Health Centre Toronto, Ontario, Canada Joanne Veldhorst, $\mathrm{RN}(\mathrm{EC}), \mathrm{BScN}$ London Intercommunity Health Centre London, Ontario, Canada

1 Patterson C. Prevention of hearing impairment and disability in the elderly. In: Canadian Task Force on the Periodic Health Examination. Canadian Guide to Clinical Preventive Health Care. OHtawa: Health Canada, 1994:954-63. http://www.ctfphc.org

2 Butler CC, van der Linden MK, MacMillan H, et al. Screening children in the first four years of life to undergo early treatment for otitis media with effusion. Cochrane Database Syst Rev 2003;(2):CD004163.

Diagnostic characteristics of the whispered voice test for detecting hearing impairment ${ }^{\star}$

\begin{tabular}{|c|c|c|c|c|c|}
\hline Number of participants & Age $(y) t$ & Sensitivity $(95 \% \mathrm{Cl})$ & Specificity (CI) & $+\mathrm{LR}$ & $-\mathbf{L R}$ \\
\hline 101 & 57 & $100(96$ to 100$)$ & 87 (80 to 92) & 7.7 & 0 \\
\hline 62 & 81 & 100 (95 to 100$)$ & 84 (71 to 92$)$ & 6.4 & 0 \\
\hline 62 & $\geqslant 55$ & 90 (82 to 95$)$ & $80(68$ to 89$)$ & 4.6 & 0.12 \\
\hline 31 & 76 & $90 \ddagger$ & $70 \ddagger$ & - & - \\
\hline 197 & 5 & 96 (82 to 99) & 92 (87 to95) & 11.6 & 0.04 \\
\hline 141 & 7.2 & 90 (69 to 97$)$ & 90 (84 to 94$)$ & 9.1 & 0.12 \\
\hline 177 & $3-12$ & 80 (68 to 88$)$ & 96 (91 to 98$)$ & 19.5 & 0.21 \\
\hline 201 & $3-7$ & $83(61$ to 94$)$ & 98 (95 to 99$)$ & 38.1 & 0.17 \\
\hline
\end{tabular}

*Diagnostic terms defined in glossary.

†Age is reported as mean or range.

$\ddagger$ Specificities were given for 2 sensitivities ( $80 \%$ and $90 \%$ ); unable to calculate $\mathrm{Cl}$ or LR. 